The Moral Landscape of War:

\title{
A Registered Report Testing how the War Context Shapes Morality's Constraints on Default Representations of Possibility
}

\author{
Hanne M Watkins \\ University of Massachusetts Amherst
}

Mark Brandt

Tilburg University

Article accepted for publication in the Journal of Experimental Social Psychology, July 2019

Author note: Correspondence concerning this article should be addressed to Hanne M. Watkins, Department of Psychological and Brain Sciences, University of Massachusetts, 135 Hicks Way, Amherst, MA 01003. E-mail: hmwatkins@umass.edu

Word count: 7829 


\begin{abstract}
Mental representations of possibility in everyday contexts incorporate descriptive and prescriptive norms. People intuitively think that $\mathrm{Mr} \mathrm{X}$ cannot perform an immoral action; even when upon deliberation they realise that the immoral action is in fact possible (Phillips \& Cushman, 2017). We replicate this "moral-possibility constraint", providing further support for the notion that default representations of possibility are - at first pass - limited to moral alternatives. We also test how context affects representations of possibility by asking whether the same findings hold in a war context. This context has different prescriptive norms (e.g., it is permissible to kill combatants, but not non-combatants), and we use Phillips and Cushman's (2017) reaction-time paradigm to test whether these prescriptive norms shape people's representations of what is possible in war. We find that the moral-possibility constraint is sensitive to variation in degree of immorality (e.g., killing a person vs. torturing a child); however the war context did not influence the constraint in the way we expected. The results further advance our understanding of the relationship between morality and domain-general cognition, and provide insight into the moral landscape of war.
\end{abstract}




\section{The Moral Landscape of War}

War is a context quite unlike peace. Broad differences between war and peace are well represented in popular culture (see e.g., Mechanic, 2016; Harrison, 2011; Hedges, 2014). Specific questions of how and why morality in war differs from morality in an everyday context have also been documented in theoretical, legal, and philosophical accounts (Fiske \& Rai, 2014). For example, there are separate bodies of law that apply during times of war (Henckaerts, Doswald-Beck, Alvermann, Dormann, \& Rolle, 2005), some subjective experiences of warfare are thought to have no "moral equivalent" during peacetime (James, 1910), and philosophers have developed distinct moral doctrines that apply (only) during times of war (Walzer, 1977). However, this theoretical interest has not yet translated into empirical work comparing the psychology of moral judgments made in a war context to moral judgments made in a peace context (for one exception see Watkins \& Laham, 2018a). In the present paper we compare moral judgments made in peace to those made in war, and we also take a further step: We investigate differences between war and peace by exploring how the relationship between moral judgments and representations of possibility compares across these two contexts.

Moral judgments evoke prescriptive norms: what should or ought to be done in a given situation. Descriptive norms, meanwhile, concern what can be done - facts about people and circumstances, regularities in behaviour, constraints of physics and probability (Cialdini, Kallgren, \& Reno, 1991). Reasoning about non-actual, alternative worlds - what could have, might have, or would have been - involves mental simulation of representations of possibility. Such reasoning can be explicit, as alternative representations of possibility are brought into conscious awareness, and are deliberated and reflected on (for a review of counterfactual reasoning, see Byrne, 2016). Explicit representations of possibility are constrained by descriptive norms and features of the situation: When we deliberate on whether Mr. 
Hypothetical is able to get to the airport on time if his car breaks down, we think "it isn't possible" if we know he's only got fifteen minutes and the nearest taxi is half an hour away (Byrne, 2016; Shtulman \& Tong, 2013).

But importantly for our purposes, Phillips and Cushman (2017) have recently suggested that reasoning about non-actual alternatives also relies on implicit representations of possibility: representations that are "rendered quickly and automatically (...) based on a distinctive set of constraints" (p. 4649). In support of their argument, Phillips and Cushman showed that such implicit, or "default", representations of possibility are distinctly constrained by prescriptive norms (in addition to descriptive norms already mentioned): When quickly judging whether an immoral act (e.g., stealing a car) is possible, "it takes time to realize that [it is in fact possible]. We begin with a default representation of possibility that tends to exclude this action, along with other immoral or irrational acts" (Phillips \& Cushman, 2017, p. 4653). It has long been known that moral values determine oughts and ought nots. Phillips and Cushman's (2017) work suggests that moral values also help determine what is intuitively possible and impossible.

The idea is that in an everyday context immorality constrains implicit representations of possibility. The scope of reasoning about non-actual alternatives is - at first pass - restricted to the moral (and therefore, possible). Imagine, for example, as above Mr. Hypothetical is on the way to the airport, when his car breaks down. In order to get to the airport on time, he steals another person's car. “He can't do that!" is an intuitive response to this scenario. Reasoning about the scenario more reflectively, however, soon reveals that Mr. Hypothetical can in fact steal a car, although he shouldn't. In an experimental demonstration of this effect, participants inaccurately responded that immoral actions were impossible (Phillips \& Cushman, 2017). In this study, participants were presented with a range of possible actions that an agent could take, in a variety of scenarios. Some actions were moral (e.g., hail a taxi), and some were immoral (e.g., steal a car). Possible but immoral acts were more likely to be erroneously judged as impossible than were possible but "ordinary" (moral) acts. Crucially, there was an interaction 
between type of action (moral vs. immoral) and time pressure condition (speeded vs. reflective), indicating that this response only emerged under time pressure. This suggests that it is the default (intuitive, implicit) representations of possibility that tend to exclude immoral actions. Once given time to reflect, however, participants tended to agree that immoral actions - while wrong - were in fact possible: The man can steal someone else's car, but he ought not to. This suggests that when under time pressure, the ought and the possible are conflated.

This implicit moral-possibility constraint is important because it is has the potential to provide insight into the context-sensitivity of the relationship between moral cognition and representations of possibility. Prescriptive norms are not identical in all places or at all times shouting at the top of your voice might be appropriate at a football game, but not while attending a classical concert. Although there is likely variation in the type and degree of variability in prescriptive norms across contexts (e.g., see Carnes, Lickel, \& Janoff-Bulman, 2015; Fiske \& Rai, 2014, Simpson, Laham, \& Fiske, 2016), there are some contextual differences in prescriptive norms which appear to be pretty clear: Thou shalt not kill - except your enemy in war. We can use this variation in prescriptive norms to extend the findings of Phillips and Cushman (2017) concerning the relationship between morality and possibility: In contexts where more potential actions are moral (e.g., "all is fair in war"), are more actions also possible? Although all might not be fair in war, the aphorism captures how moral standards - prescriptive norms - shift across contexts of war and peace. And, if all is fair in war, then there may be a wider space of intuitively possible actions in war compared to in peace. This is what we seek to test: whether context-specific changes in prescriptive norms influence default representations of possibility because these changes in context make different norms salient.

Our proposed test requires context-specific changes in prescriptive norms. It thus assumes that some everyday-immoral things become less immoral in a war context; killing someone is wrong in everyday life, but is a prototypical feature of war. While intuitively true, because this is a crucial assumption of the proposed study, we tested it in a pre-study. We 
asked 250 American residents, recruited through Amazon Mechanical Turk (AMT), to consider three scenarios set either in a war or in a peace context. For example, in one scenario (taken from Phillips and Cushman, 2017), a man's car breaks down when he is on the way to the airport. After reading each scenario, participants considered a range of target actions on behalf of the hypothetical agent and indicated how moral or immoral each action would be $(1=$ totally morally fine; 5 = totally morally wrong). There were five sets of target actions: ordinary, improbable, impossible, immoral, and immoral-plus actions. Crucially, the "immoral" actions (e.g., stealing a car, shooting a person) were judged as significantly less immoral in war $(M=3.52, S D=0.83)$ than in peace $(M=3.95, S D=0.79), t(120)=2.938, p=.004$, mean difference $=0.43,95 \%$ Cls $[0.14,0.72]$, see Figure 1 .

A wider scope of possible actions does not necessarily mean that all is fair in war. The legal and philosophical discourse on the appropriate conduct of war makes this explicit by identifying actions that are inappropriate and immoral in the war context (Henckaerts et al., 2005; Articles 48 and 51, Geneva Conventions Additional Protocol I; Watkins \& Laham, 2018b). Similarly, people (i.e., those who are not also legal and philosophical theorists) may also think that there are some things that are wrong even in war. For example, while killing an enemy soldier is morally defensible, defiling his corpse is not (Watkins \& Goodwin, 2019). This intuition was also supported by our pre-study: The "immoral-plus" actions (e.g., holding a child hostage, torturing a person) were judged as highly immoral both in war $(M=4.58, S D=0.58)$ and in peace $(M=4.53, S D=0.84), t(119)=-0.339, p=.735$, mean difference $=-0.04,95 \%$ Cls $[-$ $0.21,0.22]$, see Figure 1. 

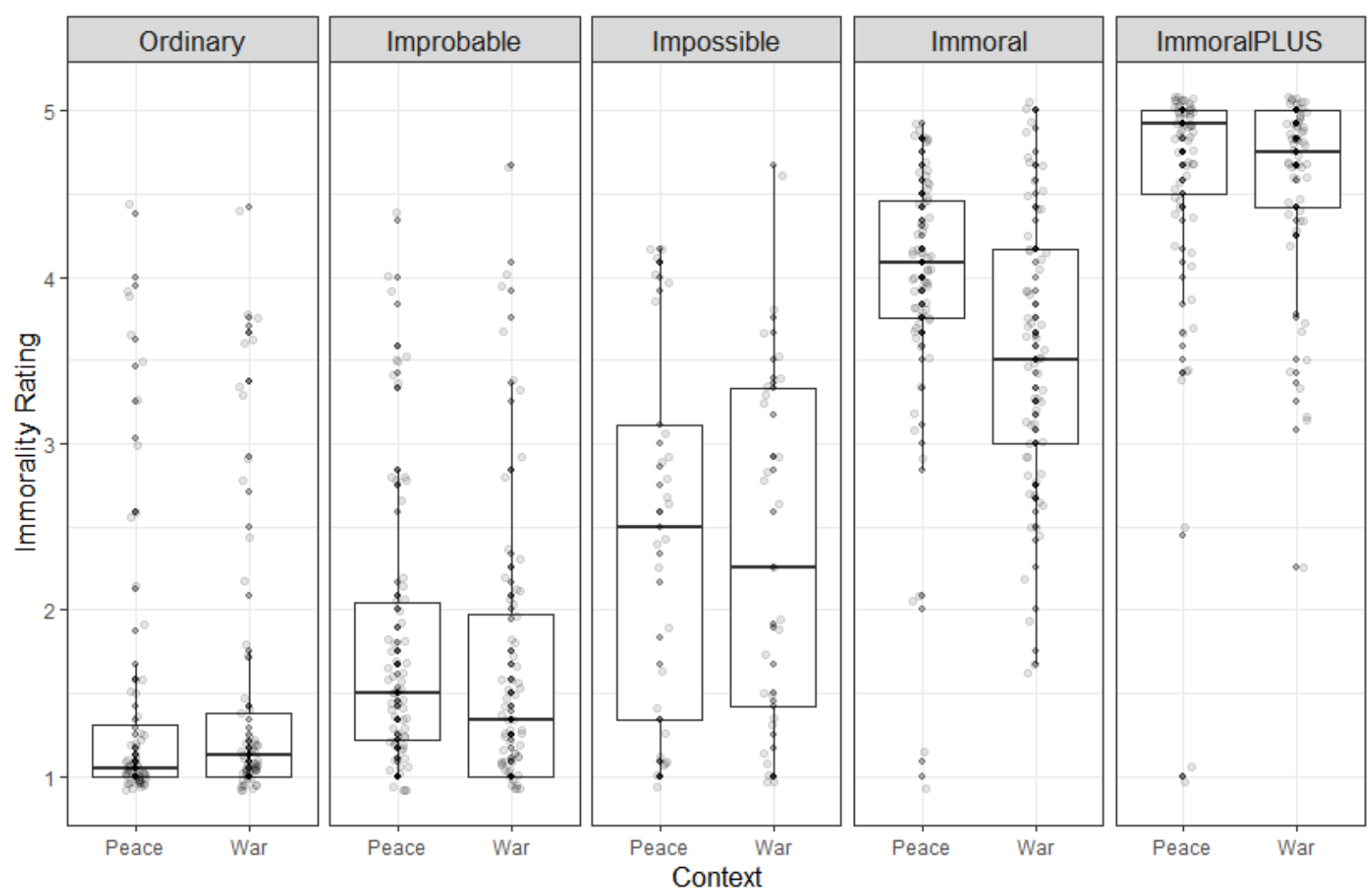

Figure 1: Illustration of the effect of context (peace vs. war) on ratings of immorality, for the five types of actions presented to participants in the pre-study. Ratings were made on a scale from 1 to 5 . The bottom and top of each box indicate the 25th and 75th percentiles, respectively. The middle horizontal line indicates the median (50th percentile). Individual data points are indicated by the grey-shaded dots.

These results support the assumption (and intuition) that while some things are fair in war, not all things are; different prescriptive norms are active in the war context compared to in the peace context. (Full details of this pre-study are provided in the Supplemental Materials, and Figure 1 illustrates the effect of context (peace vs. war) on immorality judgments for each type of action.) Thus, in studying the implicit moral-possibility constraint in a war context, we expect that an action which may be viewed as moral and impossible in an everyday context (e.g., taking a person's car without asking), becomes intuitively more moral - and perhaps it is also seen as more possible - in a war context. However, for actions that are immoral-even-in-war, the same constraints on default representations of possibility should apply. Defiling a corpse is 
not only immoral in both peace and war, it should also be intuitively judged as impossible in both contexts. If we begin with a representation of possibility that tends to exclude the immoral, then it should take time to realize that this act is in fact possible - whether conducted in peace or in war.

The current study thus takes a replication and extension approach (Bonett, 2012), building on the study by Phillips and Cushman (2017) to test three theoretically relevant questions. First, by replicating key conditions from Phillips and Cushman we will be able to test if the original moral-possibility constraint replicates in a new sample, in an additional scenario, and with an additional set of target actions. That is, Phillips and Cushman found that when under time pressure, people tended to respond that immoral acts were impossible - in many different scenarios and for many different actions, all set in an "everyday" context. We will attempt to very closely replicate this effect. ${ }^{1}$ Second, by adding a war context we will be able to test if the prescriptive norms of this context expand the scope of what is intuitively considered possible, even to previously immoral actions. Third, by adding actions that are immoral-even-inwar we will be able to test a limit of the expanded scope of possibility in the war context. These latter two questions thus represent a theoretically motivated conceptual replication of Phillips and Cushman (2017). Below we describe the materials, methods, and analyses of our proposed study. All materials are available in the Supplemental Materials and on the Open Science Framework (OSF; https://osf.io/hs58y/).

\section{The Current Study}

The current study is modelled on Phillips and Cushman (2017) Study 1a. Participants judge whether the target actions (ordinary, improbable, impossible, immoral, immoral-plus) are

\footnotetext{
${ }^{1}$ Following LeBel, Berger, Campbell \& Loving's (2017) "replication taxonomy", our replication of Phillips and Cushman would probably fall under the category of "very close replication": The IV and DV operationalizations are the same, the IV and DV stimuli are partly exactly the same and partly new (but conceptually similar), and the procedural details and physical setting will also be very similar.
} 
possible or impossible (a binary response), in war or in peace. Crucially, they make these judgments either under speeded or reflective conditions. This is important because it is under speeded conditions that we expect immorality to constrain representations of possibility; it is the interaction between time pressure and type of action that demonstrates this constraint. Under speeded conditions, Phillips and Cushman (2017) found that people were more likely to say that the immoral actions were impossible; whereas this effect of time pressure did not appear for ordinary actions (which were judged as possible under all conditions). We expect to replicate this effect in peace; observing an interaction between time pressure and type of action (immoral vs. ordinary). However, we expect that in war, because the immoral actions are no longer as immoral, they will not constrain default representations, and therefore the interaction will be attenuated and perhaps not emerge. This set of predictions implies a three-way interaction. When comparing the immoral-plus and ordinary actions, we do not expect a three-way interaction; rather, we expect that the immoral-plus actions (e.g., torturing a person) will be judged as more impossible in speeded (than reflective) conditions, in both war and peace contexts.

\section{Method}

Participants. We aimed to recruit 1600 participants, using AMT and TurkPrime. However, we ended up with 21 extra responses; the final sample was thus 1621 . We used the TurkPrime features to help ensure data quality, such as blocking repeated IP addresses and verifying that IP addresses of participants are in the U.S. Participants were compensated $\$ 0.50$, and the whole study took around 4 minutes to complete. We decided on this sample size following a series of multilevel logistic regression power analyses, using https://myshinyappsoo.shinyapps.io/multi-level-logistic-regression/ (Astivia, Gadermann, \& Guhn, 2019). With 750 participants assigned to each context (war vs. peace), in the peace context we would achieve $90 \%$ power to detect the interaction between type of action and time pressure (the key 
Phillips and Cushman, 2017, finding). We planned to exclude participants whose reaction times were substantially faster than the mean; therefore, we collected an extra 50 people in each condition. See the Results section for full details of these exclusions, and Supplemental Materials for full details of the power analyses.

\section{Materials.}

Scenarios. We selected 2 scenarios from the set used by Phillips and Cushman (2017), which were amenable to being re-written in a war context. Some of their 6 scenarios were about "handing in homework" or "working in a cafe", and were hard to reframe for war without substantially changing the content. We used the Wilderness (the agent is hiking with a group through the wilderness, then discovers they are lost) and Airport (the agent is on his way to the airport when his car breaks down) scenarios. To make the scenarios easier to adjust for the war context, we made two small alterations. We altered the Airport scenario slightly so that the agent was not traveling alone, and we altered the Wilderness scenario slightly so that the agent was leading the group, rather than merely a part of it. We also wrote a third, new, scenario (Shopping Trip) in which the agent is going shopping on his day off, when a threatening man runs towards him. In all scenarios, the agents were described as male (either as men or soldiers) because most soldiers are still male (Office of the Deputy Assistant Secretary of Defense, 2013). In all the scenarios, the agent faces a challenging situation, and must decide what to do.

Target actions. For each scenario, we wrote 24 target actions; that is, the actions that the participant considers on behalf of the agent in the scenario. There were 8 ordinary, 4 improbable, 4 impossible, 4 immoral, and 4 immoral-plus actions for each scenario.

For the Airport and Wilderness scenarios we were able to use the ordinary, improbable, impossible, and immoral actions from Phillips and Cushman (2017). For example, an ordinary action in the Wilderness scenario was "create a shelter to stay warm". An improbable action was 
"find thermal vent to keep warm," while an impossible action was "grind up rocks for food and water". An immoral action in this scenario was "rob other hikers they meet". We made a few minor alterations when the actions were set in the war context (for example, we changed "phone" to "radio", and "rob other hikers" became "rob any civilians"). ${ }^{2}$ For the new Shopping Trip scenario, we wrote new ordinary, impossible, improbable, and immoral actions modelled on the ones used by Phillips and Cushman (2017).

The immoral-plus actions were an extension of the materials, and were actions that would be seen as immoral even in war. For example, in the Airport scenario a "merely" immoral action was "take a taxi without paying", while an immoral-plus action was "kill a person/civilian to take their car". Some of the original immoral actions seemed likely to be seen as immoral even in war (e.g., "leave the weakest people behind" in the Wilderness scenario), in which case they were moved to the immoral-plus set, and we wrote new merely-immoral actions. As mentioned above, these actions were pre-tested; the immoral actions were affected by context (they were judged as less immoral in war than in peace), whereas the immoral-plus actions were not affected by context (they were judged as equally immoral in war and in peace). See Supplemental Materials for full details of this pre-test.

Procedure. Like Phillips and Cushman (2017), we ran the main study using Testable, an online survey software which enables the presentation of stimuli under timed conditions in online studies. Participants started by providing basic demographic information (age, gender, education, and handedness), and calibrating their screens. They were then randomly assigned to either the speeded or the reflective condition, and either the war or the peace context. There were thus 4 between-subject cells in the present design, while type of action (a factor with 5 levels: ordinary, improbable, impossible, immoral, immoral-plus) was varied within subjects. All

\footnotetext{
${ }^{2}$ We did not use the irrational actions from Phillips and Cushman (2017): These actions were important for their purposes of establishing the validity of the paradigm, but they are less relevant to our research questions.
} 
materials are in the Supplemental Materials; and details of the study file for Testable is also available online: https://osf.io/hs58y/

Practice trials. First, all participants were familiarized with the task in a practice block. They used their keyboard to press the "f" key for impossible actions, and the "j" key for possible actions, when the target actions appeared on the screen. Therefore, in 20 practice trials, the words "impossible" or "possible" appeared on the screen (10 of each, in a random order), and participants responded using the appropriate key. If they responded incorrectly, they received feedback. In the speeded condition, this feedback was "That's not right! Possible is [f]. Get ready to keep going." Participants in this condition had $1550 \mathrm{~ms}$ in which to make a response. In the reflective condition, the feedback was "That's not right! Possible is [f]. Please slow down and answer correctly." In this condition the response window did not time out.

Experimental procedure. After the practice, the context manipulation was introduced. Participants received information about the upcoming task, emphasizing either war or peace. For example, in the war context, they read the following text: "In this part, you will read a story and say whether different actions are possible or impossible. These stories are all about soldiers, operating in a war zone and facing various potentially challenging situations. Please take a moment to think about what this may be like." The introductory text was also accompanied by a photo, either depicting soldiers walking through a war zone, or people walking on a city street. In the speeded condition, the following text appeared after the introduction: "Please answer as quickly and as accurately as you possibly can. You will only have about 1 second to respond to each event." In the reflective condition, this text was: "Please take your time and carefully reflect on these questions. Make sure you do not answer too quickly or carelessly."

Participants then responded to the three scenarios described above: Wilderness, Airport, and Shopping trip; under either speeded or reflective conditions. Each scenario was presented on a separate screen, and participants were given time to read it (i.e., this screen did not time 
out). After participants read the scenario they pressed the spacebar to move to the next screen, where the following text was presented: "Given [agent's] situation, please tell us whether it is possible or impossible for [agent] to do the following things. Press [space] when you are ready to begin." On this screen they were also reminded of the (lack of) time pressure, with the text "Remember, this will go very quickly!" (vs. "Remember to slowly and carefully consider each event!"). Then, the target actions appeared on the screen, one at a time, and participants indicated whether the action was "possible" or "impossible" using the appropriate key. They received no accuracy feedback. In the speeded condition, they had $1550 \mathrm{~ms}$ in which to respond, before the next target action appeared. In the reflective condition, the response window did not time out. After responding to all 16 target actions for one scenario, the next scenario appeared.

For each scenario, participants always responded to the ordinary actions, and to the impossible actions for that scenario. But, they only responded to either the improbable, or the immoral, or the immoral-plus actions for each scenario. Combinations of type of action and scenario were varied in a latin square, such that across participants, all scenarios appeared with all types of action. The order of presentation of scenarios, and target actions for each scenario was randomized for each participant. At the end, participants were thanked and debriefed.

\section{Results}

The full analysis script in $\mathrm{R}$ (and full data set) are available on the OSF (https://osf.io/dgzye/). We also provide the script we used to combine individual Testable files (i.e., each participant's response file $)^{3}$ into a single data file, here: https://osf.io/3ru2z/

Participant exclusions. We first removed practice trials and time-outs (i.e., trials on which the participant did not respond; $7.3 \%$ of all responses) as well as "outlier responses" (defined by Phillips and Cushman as $>6,000 \mathrm{~ms} ; 2.1 \%$ of all responses). Next, we calculated

\footnotetext{
${ }^{3}$ We do not provide the individual response files themselves, because they are not de-identified.
} 
each participant's average response time, and excluded all trials from any participants whose average response time was $<800 \mathrm{~ms}$ in the speeded condition or $<1,000 \mathrm{~ms}$ in the reflective condition. Based on Phillips and Cushman (2017), we expected to exclude approximately 6\% of participants at this point, and indeed, this criteria excluded $5.7 \%$ of our participants (29 people in the reflective condition, and 64 in the speeded condition). Further, if a response on any single trial was given in less than 500 ms, data from that trial was excluded (this criterion removed 1\% of the remaining responses). And, if a response on any single trial in the reflective condition was given in less than $1,500 \mathrm{~ms}$, data from that trial was excluded. This criterion removed a further $26.9 \%$ of individual responses. Phillips and Cushman (2017) report in the Supplemental Materials that when this final exclusion criterion is not applied, the same pattern of results emerges; we therefore also analysed the data without these final exclusions. The results were broadly consistent; we provide the full analyses in the Supplemental Materials, and note in the analysis section (below) any effects that differ when these final exclusions are not applied. However, as planned, we base our main interpretation and conclusions on the data set with exclusions.

Planned analyses. We first analysed the data in a mixed effects model, using the Ime4 and ImerTest packages in $R$ (Bates, Maechler, Bolker \& Walker, 2015; Kuznetsova, Brockhoff, Christensen, 2017). To first replicate Phillips and Cushman (2017), we selected only the peace context, and regressed the response variable (possible vs. impossible) on time pressure condition (speeded vs. reflective), type of action (5 levels), and their interaction. We also entered scenario as a random intercept, and the effect of type of action was set to vary across participants (random slope). The key effect is the interaction between type of action and time 
pressure condition, which indicates the moral-possibility constraint: As expected, this interaction was significant, $\mathrm{X}^{2}(4)=166.72, p<.001 .^{4}$

To break down this interaction, we tested the effect of condition (speeded vs. reflective) for each type of action separately (as planned). As expected, the immoral and immoral-plus actions were judged as more impossible in the speeded condition than the reflective condition (immoral: $\mathrm{B}=-0.562, \mathrm{SE}=0.15, p<.001$; immoral-plus: $\mathrm{B}=-1.888, \mathrm{SE}=0.22, p<.001$ ). $\mathrm{A}$ post hoc analysis shows that the effect of condition was significantly and substantially greater for immoral-plus than immoral actions, $\mathrm{B}=-1.337, \mathrm{SE}=0.20, p<.001$. In other words, in the peace context we have replicated the moral-possibility constraint originally observed by Phillips and Cushman (2017) and additionally found that the effect is larger for immoral-plus actions.

Further, the ordinary and improbable actions were not affected by condition (ordinary: B $=-0.088, \mathrm{SE}=0.14, p=0.528$; improbable: $\mathrm{B}=-0.086, \mathrm{SE}=0.11, p=0.424) .{ }^{5}$ The impossible actions appeared to be affected by condition, such that these actions were judged as more possible in the speeded than the reflective condition; however, our pre-planned model failed to converge when we selected only this type of action. We therefore simplified the model slightly by taking out the random effect of scenario. In this model, the effect of condition was significant for the impossible actions: $\mathrm{B}=0.948, \mathrm{SE}=0.11, p<.001$. Although these comparisons are not central to our hypotheses, they are consistent with Phillips and Cushman's (2017) findings.

\footnotetext{
${ }^{4}$ This test-statistic was derived using the same method as Phillips and Cushman (2017): We first fitted a model without the interaction, then added the interaction, and compared the two models. The significant $\chi^{2}$ value indicates that the interaction improved the fit of the model. We pre-registered that we would use ImerTest to compute t-statistics and p-values; however, this only provides the test statistics for a specific component of the interaction. This made the analyses less comparable. Therefore, we used the same method as Phillips and Cushman (2017), although the conclusions are the same regardless. Full details of all analyses are in the code, here osf.io/7wa4p

${ }^{5}$ In the Supplemental Analyses (using dataset without the final exclusions), the ordinary and improbable actions were also affected by condition, such that participants were more likely to (erroneously) judge them as impossible in the speeded (than the reflective) condition; see Figure S2.
} 


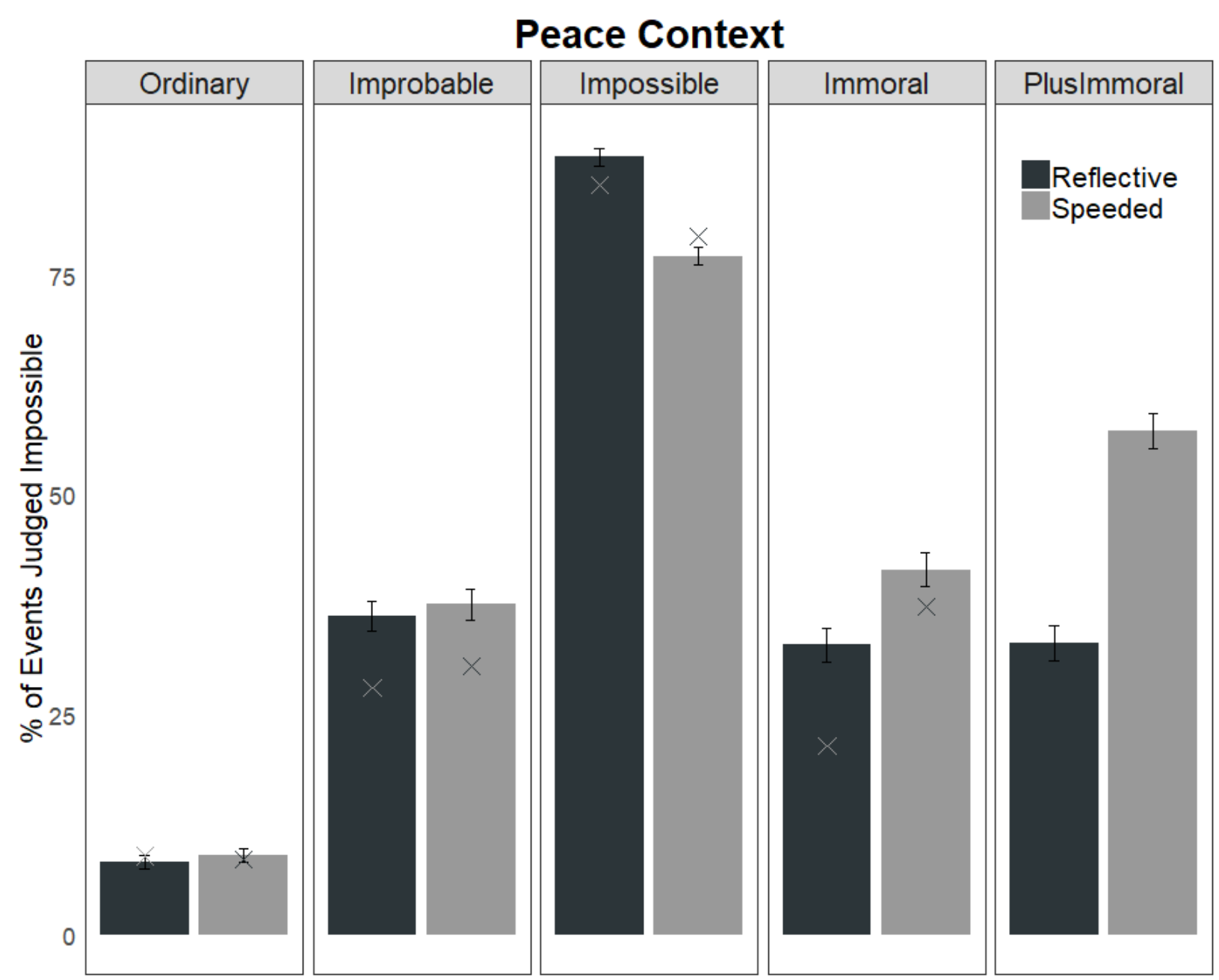

Figure 2: Illustration of the effect of time pressure condition (reflective vs. speeded) in the peace context, for each type of action. Error bars represent $+/-1$ standard error of the mean. The $\mathrm{X}$ represents the results presented in Figure 1 of Phillips and Cushman (2017). There are no X's in the PlusImmoral panel because Phillips and Cushman (2017) did not include this type of action.

Based on Phillips and Cushman (2017), we also expected (and found) an effect of type of action, such that ordinary actions were judged as the most possible, and impossible actions were judged as the least possible. Figure 2 illustrates these effects in the peace context. We urge the reader to compare our Figure 2 with Figure 1 in Phillips and Cushman (2017). The results are quite consistent. 
Second, we undertook the same analyses in only the war context; regressing the response variable on time pressure condition, type of action, and their interaction (and with scenario as a random intercept, and a random slope of type of action by participant). In this context, we again expected, and found, a significant interaction between type of action and time pressure condition, indicating a moral-possibility constraint, $x^{2}(4)=105.42, p<.001 .6$ However, in this context we expected that the interaction would be driven primarily by the immoral-plus actions being judged as more impossible in the speeded condition than in the reflective condition (while the ordinary, improbable, impossible, and merely-immoral actions would not be affected by condition). This is not what we found.

Rather, similarly to the peace context, when analysing the effect of condition (speeded vs. reflective) for each type of action separately, we found that both the immoral and the immoral-plus actions were affected by condition (immoral: $\mathrm{B}=-0.862, \mathrm{SE}=0.18, p<.001$; immoral-plus: $\mathrm{B}=-1.409, \mathrm{SE}=0.28, p<.001)$. As in the peace context, both the immoral and immoral-plus actions were judged as more impossible in the speeded than the reflective conditions, indicating a moral-possibility constraint. However, a post hoc analysis again revealed that the effect of condition was significantly greater for the immoral-plus than immoral actions, $B=-0.631, S E=0.28, p=.025 .^{7}$

\footnotetext{
${ }^{6}$ As with the peace context, we originally planned a slightly different analysis, but switched to the approach used by Phillips and Cushman (2017) to maintain consistency.

7 In the Supplemental Analyses, this effect was not significant. That is, when not applying the final exclusions to the data set, we do not find evidence that the moral-possibility constraint is significantly larger for the immoral-plus than the immoral actions, in war.
} 


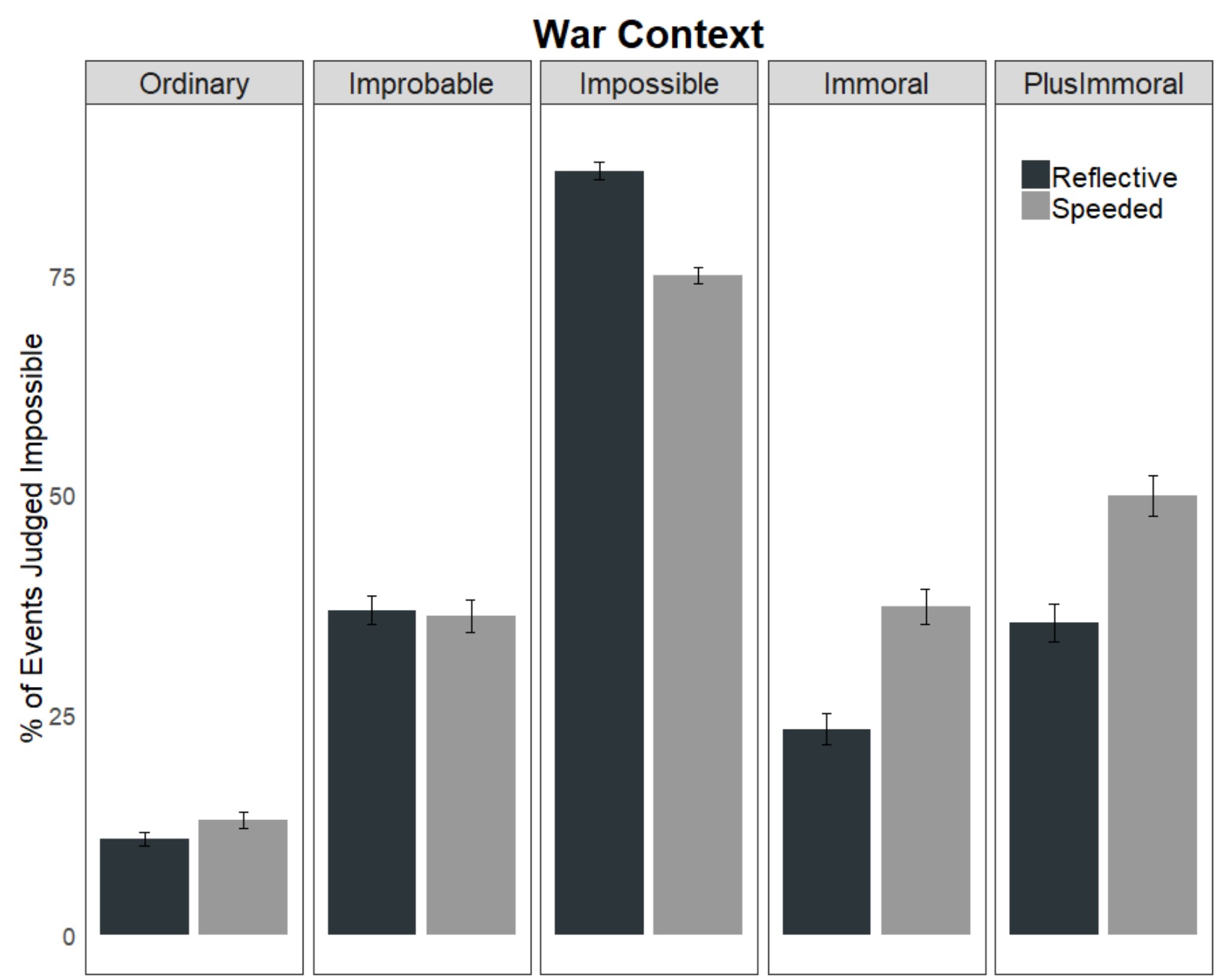

Figure 3: Illustration of the effect of time pressure condition (reflective vs. speeded) in the war context, for each type of action. Error bars represent $+/-1$ standard error of the mean.

In the war context, as in the peace context, the ordinary and improbable actions were not affected by time pressure condition (ordinary: $\mathrm{B}=-0.135, \mathrm{SE}=0.12, p=.260$; improbable: $\mathrm{B}$ $=0.010, \mathrm{SE}=0.12, p=.928$, while the impossible actions were judged as less impossible in the speeded condition (compared to the reflective condition; $\mathrm{B}=1.256$, $\mathrm{SE}=0.10, p<.001$ ). These results are illustrated in Figure $3 .^{8}$

\footnotetext{
${ }^{8}$ Compare Figure S3 in the Supplemental Analyses - in these analyses, the ordinary actions were also affected by condition.
} 
Finally, we investigated whether context moderated the interaction between type of action and condition. This analysis was undertaken using the full data set, including both war and peace contexts. We regressed the response (possible vs. impossible) on the three-way interaction between context, time pressure condition, and type of action, all two-way interactions, and all three main effects. We also entered scenario as a random intercept, and the effect of type of action was set to vary across participants. We expected that the three-way interaction (between immoral actions, time pressure, and context) would be significant. This interaction was not significant: $B=-0.180, S E=0.25, p=.478$. Because of this lack of significance, as planned, we conducted an equivalence test. Our smallest effect size of interest was $B=|0.35|$ (see Supplemental Materials). The $90 \%$ confidence interval around our observed effect includes the smallest effect size of interest: $[-0.596,0.237]$. We thus have an inconclusive pattern of effects; the effect is not statistically different from 0 , but nor can we conclude (at $p$ $<.05$ ) that it is so small as to be uninteresting (Rainy, 2014; Lakens, 2017).

Unexpectedly, we did find a significant three-way interaction between immoral-plus actions, time pressure, and context: $\mathrm{B}=0.917, \mathrm{SE}=0.35, p=.008$. This interaction indicates that the effect of time pressure on these actions differs across war and peace contexts. In the peace context, the immoral-plus actions are judged as significantly more impossible under speeded compared to reflective conditions (indicating a moral-possibility constraint, $\mathrm{B}=-1.888$, $\mathrm{SE}=0.22, p<.001$, see above). This effect is significant also in the war context; however it is not as large $(B=-1.409, \mathrm{SE}=0.28, p<.001$; see above $) .{ }^{9}$

\footnotetext{
${ }^{9}$ While this pattern of coefficients also emerged in the Supplemental Analyses, the three-way interaction between immoral-plus actions, condition, and context was not significant when using the full data set; $\mathrm{B}=$ $0.274, \mathrm{SE}=0.15, p=.061$. And a $90 \% \mathrm{Cl}$ around this effect also included the SESOI, [0.033, 0.515], which indicates an inconclusive pattern of results for this type of action. Further, the full model failed to converge using the full data set, and these effects were therefore estimated using a model which did not include a scenario random intercept or a random slope of type of action.
} 
The attenuation of the moral-possibility constraint for these immoral-plus actions in war appears to be driven by the speeded condition. In this condition, the immoral-plus actions are judged as less impossible in war compared to in peace: $\mathrm{B}=0.559, \mathrm{SE}=0.20, p=.005$. Whereas in the reflective condition, there is no significant difference across war and peace in how possible (or impossible) the immoral-plus actions are judged: $\mathrm{B}=-0.194, \mathrm{SE}=0.27, p=$ $.467 .{ }^{10}$ In short, our pre-registered hypothesis was that the war context would make immoral actions appear more possible in the speeded condition, but instead we found that the war context made the immoral-plus actions appear more possible in the speeded condition.

\section{Discussion}

The present study aimed to replicate and extend the study by Phillips and Cushman (2017). Below we discuss the results of the replication and extension components in turn.

\section{Successful Replication}

Phillips and Cushman (2017) showed that under time pressure, people intuitively respond that immoral actions are impossible (rather than possible); we refer to this as the moralpossibility constraint. Our study replicates this constraint, in a new sample (recruited using the same methods), in a new scenario (in addition to two of the original scenarios), and for a new set of actions (in addition to the original actions). Our discovery that the moral-possibility constraint is robust to small variations in methodology and sample will be reassuring for researchers planning to build on these findings.

This constraint may occur because it is easier to bring normative actions to mind than counter-normative actions (Kahneman \& Miller, 1986). When considering non-actual alternatives (i.e., counterfactuals), we do not think of all of the possible alternatives. Rather, the set of alternatives we consider is constrained to a particular "domain of possibility": We don't

\footnotetext{
10 These final comparisons were conducted post-hoc; the relevant code has been added to the analysis script and is marked "exploratory".
} 
(generally) entertain physically impossible, extremely improbable, or highly immoral and counter-normative options (Byrne, 2016; Phillips \& Knobe, 2018). Although people have the ability to counterfactually consider such events, they are not typically generated spontaneously. Possible, probable, and normative options, however, are much more likely to spontaneously come to mind when considering counterfactuals (Byrne, 2016), just as they are more likely to come to mind in other situations (Phillips \& Knobe, 2018). Phillips and Cushman (2017)'s study and our replication - demonstrates that the way the domain of possibility is circumscribed leads to a particular kind of error when quickly considering immoral counterfactual alternatives available to an agent: These are intuitively judged as impossible - i.e., outside the domain of possibility - despite being in actual fact physically possible.

Our results can thus both be explained by, and provide evidence for, the idea that by default, the domain of possibility excludes immoral actions. The exact mechanism by which prescriptive norms are integrated into the domain of possibility is still not clear and is under active research (see Phillips \& Knobe, 2018, for a review). One intriguing line of reasoning suggests that moral, physical, and probabilistic properties of a given scenario all influence counterfactual reasoning (as well as other processes, including judgments of freedom, and causal selection) by shaping a single mental representation of that scenario (i.e., rather than having independent effects on counterfactual reasoning and the other processes, Phillips \& Knobe, 2018). Future research could combine manipulations of immorality with manipulations of probability and physics, to further probe these relationships.

\section{Extensions to War and Immoral-Plus Actions}

We also aimed to extend the original Phillips and Cushman (2017) findings in two related, theoretically important, directions: First, by adding a war context (to the "everyday" peace context of the original paper we hoped to test whether the (more lenient) prescriptive norms of this context would expand the scope of what is intuitively considered possible, even to previously immoral actions. In other words, do the boundaries of the domain of possibility 
expand or contract depending on the context under consideration? This is important because Phillips and Cushman (2017) suggest that default representations of an action's possibility are flexibly constrained by the (im)morality of that action, depending on the prescriptive norms in a given context. In war, different prescriptive norms apply (see our pre-test); we therefore expected participants to make different intuitive judgments of possibility in this context as well.

Second, by adding actions that were immoral-even-in-war, we aimed to test a limit on the expanded scope of possibility in the war context. It is not the case that all is fair in war: In our pre-test, moral judgments of immoral-plus actions were unaffected by the context manipulation; they were seen as morally wrong in both war and peace. These actions thus tap into prescriptive norms which a priori appear not to vary across war and peace; for these actions we therefore did not expect participants to make different intuitive judgments of possibility across contexts.

These two extensions both represent ways of investigating the question of whether the relationship between moral cognition and representations of possibility is sensitive to changes in prescriptive norms (as operationalized using war vs. peace contexts and immoral vs. immoralplus actions). In support of such context-sensitivity, we expected to find a three-way interaction between immoral actions, time pressure condition, and context, such that in the peace context, the moral-possibility constraint would emerge for the immoral actions, whereas in the war context it would not (or it would be attenuated). This three-way interaction was not significant, suggesting that the moral-possibility constraint does not differ by context.

Since we did, however, find that the immorality judgments of these actions were affected by context (in the pre-study), one interpretation of this (lack of a) context effect could be that immorality is sufficient but not necessary for constraining default representations. Another interpretation could be that the immoral actions are still seen as immoral in war, but in the prestudy participants were overriding their intuitive, default judgment. That is, the fact that these actions constrained default representations of possibility could indicate "true" immorality. These 
were the interpretations we considered during the planning of this study. However, the equivalence test suggests that we cannot conclusively claim that the interaction effect is smaller than our SESOI $(B=|0.35|)$. It could be the case - despite our sample size and power estimates - that we did not have enough power to reliably detect differences (of the size we observe) when it comes to the relationship between (plain im)morality and possibility across war and peace contexts. Because of this ambiguity, and the results for the immoral-plus actions, we now favour an alternative interpretation (described below).

For the immoral-plus actions, we did find a significant three-way interaction between immoral-plus actions, time pressure condition, and context. For these actions we were not expecting a three-way interaction; rather, because of the extremity of these immoral actions, we expected that the moral-possibility constraint would emerge in both peace and war contexts. And, indeed, the interaction between time pressure condition and type of action emerged for the immoral-plus actions in both peace and war contexts - but it was significantly larger in the peace context, which we had not expected. Post hoc analyses further revealed that in both peace and war contexts, the effect of time pressure condition was larger for immoral-plus than for "merely" immoral actions.

Taken together, our results thus appear to indicate that default representations of an action are indeed sensitive to the (im)morality of that action - the moral-possibility constraint varied in magnitude depending on other experimental factors. However, it was not necessarily context (war vs. peace) - the experimental factor we emphasized the most - that had the most consistent effect. Rather, it was the degree of immorality (merely immoral vs. immoral-plus) that most reliably influenced the magnitude of the moral-possibility constraint. In other words, although the default representations of an action's possibility may be flexibly constrained by the (im)morality of that action, this flexibility "directly" depends on the strength of the prescriptive norms, more so than depending on a given context. Although the context changes the strength of (some) norms, this cross-context variability (both in judgments of morality and possibility) is 
much smaller than the cross-norm variability. As an example, for the immoral-plus actions, going from a peace context to a war context reduced the moral-possibility constraint by $26 \%$ (i.e., the effect of time pressure condition was -1.888 in peace, and -1.409 in war). Whereas in the peace context, going from merely-immoral to immoral-plus actions increased the moralpossibility constraint by $336 \%$ (i.e. the effect of time pressure condition was -0.562 for immoral actions, and -1.888 for immoral-plus actions).

\section{Implications}

These results have both practical and theoretical implications. For researchers interested in the relationship between morality and representations of possibility (or, more broadly, reasoning about non-actual alternative worlds), our results demonstrate that not only are default representations constrained by immorality; they are constrained even more by even worse immorality. They are also somewhat less constrained in war (a context in which some generally immoral things are seen as less immoral), but the larger effect comes "directly" from degrees of immorality. This further builds on a point made by Phillips and Cushman (2017, p. 4653) who suggest that "morality shapes how we think about many things because it constrains the very possibilities that come to mind."

To explain this difference in the size of the effect, consider again the domain of possibility: As we've demonstrated, some (actually possible) immoral actions are intuitively excluded from this domain. Is this exclusion one half of a dichotomy, such that any action is represented as either inside or outside the domain? Or is there a sense in which some possibilities are even "further outside" the domain than others? Phillips and Knobe (2018) suggest that the answer is "both (p.89) "each possibility would be represented as either inside or outside the domain. The appearance of gradability [arises] because some possibilities would have a higher probability of being represented inside the domain than others." While not set up to test this idea directly, our findings are consistent with this analysis. Future research could manipulate and measure immorality in a more continuous fashion (rather than comparing 
merely-immoral to immoral-plus categories), in order to further investigate probabilities of inclusion and the relationship between possibility and morality.

The present results also provide insight into the moral landscape of war. Legal and philosophical scholars of war treat war and peace as distinct, and very different, spheres of (moral) action. We shared this intuition, which in turn gave rise to the concern that in the empirical domain of moral psychology, the conclusions of legal and philosophical scholars of war are largely ignored; researchers instead behave as if morality in war and peace are equivalent by using war-based scenarios interchangeably with scenarios set in an everyday context (see e.g., Colby \& Kohlberg, 1987; Uhlmann, Pizarro, Tannenbaum, \& Ditto, 2009.; Young \& Phillips, 2011). The present study was therefore partly intended to shed light on whether such an interchangeability is in fact warranted (see also Watkins, 2019). Based on the results, we are now less inclined to say that such interchangeability is problematic; attention should still be paid to differences between war and peace in general and in the domain of moral judgment, but we are no longer as concerned that representations of possibility (default or deliberative) are processed in a drastically different way across the two contexts. It's a matter of degree, but a smaller degree and in a different form than we anticipated.

\section{Limitations and Future Directions}

One potential limitation of the present study is its use of text-based scenarios to assess (moral) cognition. The differences between stimuli presented to participants and the "real world" situations those scenarios represent requires some unpacking for any research (Blascovich, Loomis, Beall, Swinth, Hoyt, \& Bailenson, 2002), but the differences seem particularly striking when the scenarios are set in war - a context which, as William James maintained, has no "moral equivalence" in peace time (1910).

There are at least two reasons for being optimistic about the validity of the present study's findings. Hainmueller, Hangartner, and Yamamoto (2015) recently compared hypothetical choices to actual choices in a referendum in Switzerland, and found that the 
experiments performed "remarkably well in capturing the structural effects of attributes that drive [behavior]" (p. 6, Hainmueller et al., 2015). We would never suggest that responding to vignettes in a war context is the same as actually being in that context; however, mental representations of possibility, and their relationship to moral judgment, may be effectively simulated - in war as well as in peace - by third-party observers in the lab. ${ }^{11}$ The second is that scenarios set in a war context (as compared to a peace context) have successfully been used in previous experimental studies investigating differences in moral judgment as they relate to ingroup versus outgroup relations during conflict (Watkins \& Laham, 2018a, Pratto \& Glasford, 2008). Nonetheless, future research could use more enriched scenarios - for example, by using video games (Molenberghs, Ogilvie, Louis, Decety, Bagnall, \& Bain, 2015) or virtual reality (Blascovich et al., 2002; Patil, Zanon, Novembre, Zangrando, Chittaro, \& Silani, 2018) - or conduct similar studies with actual combatants (de Graaff, Schut, Verweij, Vermetten, \& Giebels, 2016).

A second limitation is that our participants were recruited using MTurk. MTurk participants tend to be younger, more educated, and more liberal compared to the general U.S. population (Berinsky, Huber, \& Lenz, 2012; Shapiro, Chandler, \& Mueller, 2013), but it is unknown what their veteran status is. Given the prevalence of veterans in the general U.S. population (7\% in 2016; Bialik, 2017), it is unlikely that there would be enough people in our sample with combat experience to conduct quantitative comparisons. When Watkins and Goodwin (2019) asked 134 MTurk participants about their veteran status, 5 individuals (3.7\%, $95 \%$ Cls $[2.88,4.52])$ reported that they personally had military experience. However, it is an interesting question whether direct experience moderates the moral-possibility constraint. This

\footnotetext{
${ }^{11}$ We also note that we are in the present study modeling the cognition of external judges, not the actual actors - i.e., Hainmueller et al modelled hypothetical choice and real choice - and (speculatively) a hypothetical judgment seems less distinct from a real judgment.
} 
is relevant not only to military personnel, but also to civilians who have experienced war personally. ${ }^{12}$ Future research should investigate these important populations as well.

\section{Conclusion}

We replicated the finding that morality constrains the default representation of the possible. Unexpectedly, we also found that this effect is even stronger for even more immoral actions and that the context of war can have a small effect on these representations. Although our pre-registered hypotheses were not supported, our findings solidify the original work on immorality and representations of the possible and suggest new avenues for understanding morality's constraints on cognition.

\footnotetext{
12 We would like to thank an anonymous reviewer for this suggestion.
} 


\section{References}

Article 48: Additional Protocol (I) to the Geneva Conventions, relating to the Protection of Victims of International Armed Conflicts, 8 June 1977. Retrieved March 1, 2016, from http://www.icrc.org/ihl/WebART/470-750054?OpenDocument

Article 51: Additional Protocol (I) to the Geneva Conventions, relating to the Protection of Victims of International Armed Conflicts, 8 June, 1977. Retrieved March 1, 2016, from http://www.icrc.org/ihl/WebART/470-750054?OpenDocument

Astivia, O., Gadermann, A., \& Guhn, M. (2019). The relationship between statistical power and predictor distribution in multilevel logistic regression: a simulation-based approach. BMC Medical Research Methodology, 19(1), 97-117. doi.org/10.1186/s12874-019-0742-8

Bates, D., Maechler, M., Bolker, B., Walker, S. (2015). Fitting Linear Mixed-Effects Models Using Ime4. Journal of Statistical Software, 67(1), 1-48. doi:10.18637/jss.v067.i01

Berinsky, A. J., Huber, G. A., \& Lenz, G. S. (2012). Evaluating online labor markets for experimental research: Amazon. com's Mechanical Turk. Political analysis, 20(3), 351368. doi.org/10.1093/pan/mpr057

Bialik, K. (2017). The changing face of America's veteran population. Article published by the Pew Research Center, November 10, 2017. Retrieved October 16, 2018, from http://www.pewresearch.org/fact-tank/2017/11/10/the-changing-face-of-americasveteran-population/

Blascovich, J., Loomis, J., Beall, A. C., Swinth, K. R., Hoyt, C. L., \& Bailenson, J. N. (2002). Immersive virtual environment technology as a methodological tool for social psychology. Psychological Inquiry, 13(2), 103-124. doi.org/10.1207/S15327965PLI1302_01

Bonett, D. G. (2012). Replication-extension studies. Current Directions in Psychological Science, 21(6), 409-412. doi:10.1177/0963721412459512 
Byrne, R. M. J. (2016). Counterfactual thought. Annual Review of Psychology, 67(1), 135-157. doi:10.1146/annurev-psych-122414-033249

Carnes, N. C., Lickel, B., \& Janoff-Bulman, R. (2015). Shared perceptions: Morality is embedded in social contexts. Personality and Social Psychology Bulletin, 41(3), 351362. doi.org/10.1177/0146167214566187

Cialdini, R. B., Kallgren, C. A., \& Reno, R. R. (1991). A focus theory of normative conduct: A theoretical refinement and reevaluation of the role of norms in human behavior. In Advances in Experimental Social Psychology (Vol. 24, pp. 201-234). Cambridge, MA: Academic Press, Inc.

Colby, A., \& Kohlberg, L. (1987). The Measurement of Moral Judgement: Volume 2, Standard Issue Scoring Manual. Cambridge, UK: Cambridge University Press.

de Graaff, M. C., Schut, M., Verweij, D. E., Vermetten, E., \& Giebels, E. (2016). Emotional reactions and moral judgment: the effects of morally challenging interactions in military operations. Ethics \& Behavior, 26(1), 14-31. doi.org/10.1080/10508422.2014.975815

Fiske, A. P., \& Rai, T. S. (2014). War. In A.P. Fiske, \& T.S. Rai. (Authors), Virtuous Violence (pp. 93-106). Cambridge, UK: Cambridge University Press.

Hainmueller, J., Hangartner, D., \& Yamamoto, T. (2015). Validating vignette and conjoint survey experiments against real-world behavior. Proceedings of the National Academy of Sciences, 112(8), 2395-2400. doi.org/10.1073/pnas.1416587112

Harrison, C. Y. (2011). Generals die in bed. London, UK: Random House.

Hedges, C. (2014). War is a force that gives us meaning. New York, NY: Public Affairs. Henckaerts, J.-M., Doswald-Beck, L., Alvermann, C., Dormann, K., \& Rolle, B. (2005). Customary International Humanitarian Law. Cambridge, UK: Cambridge University Press

James, W. (1910). The moral equivalent of war. (Kindle Edition, 2011). Cambridge, MA: Charles Rivers Editors. 
Kahneman, D., \& Miller, D. T. (1986). Norm theory: Comparing reality to its alternatives. Psychological Review, 93(2), 136-153.

Kuznetsova, A., Brockhoff, P.B., Christensen, R.H.B. (2017). ImerTest Package: Tests in Linear Mixed Effects Models. Journal of Statistical Software, 82(13), 1-26. doi:10.18637/jss.v082.i13.

Lakens, D. (2017). Equivalence tests: a practical primer for t tests, correlations, and metaanalyses. Social Psychological and Personality Science, 8(4), 355-362. doi/10.1177/1948550617697177

LeBel, E. P., Berger, D., Campbell, L., \& Loving, T. J. (2017). Falsifiability is not optional. Journal of Personality and Social Psychology, 113(2), 254-261. doi:10.1037/pspi0000106

Mechanic, B. (Producer), \& Gibson, M. (Director). (2016). Hacksaw Ridge [Motion picture]. United States: Summit Entertainment.

Molenberghs, P., Ogilvie, C., Louis, W. R., Decety, J., Bagnall, J., \& Bain, P. G. (2015). The neural correlates of justified and unjustified killing: an fMRI study. Social Cognitive and Affective Neuroscience, 10(10), 1397-1404. doi:10.1093/scan/nsv027

Office of the Deputy Assistant Secretary of Defense (Military Community and Family Policy). (2013). 2013 Demographics: Profile of the Military Community. Retrieved January, 2016, from Military OneSource: http://www.militaryonesource.mil/footer?content_id=267470

Patil, I., Zanon, M., Novembre, G., Zangrando, N., Chittaro, L., \& Silani, G. (2018).

Neuroanatomical basis of concern-based altruism in virtual environment. Neuropsychologia, 116, 34-43. doi.org/10.1016/j.neuropsychologia.2017.02.015

Phillips, J., \& Cushman, F. (2017). Morality constrains the default representation of what is possible. Proceedings of the National Academy of Sciences of the United States of America, 114(18), 4649-4654. doi:10.1073/pnas.1619717114

Phillips, J., \& Knobe, J. (2018). The psychological representation of modality. Mind \& Language, 
33(1), 65-94. doi.org/10.1111/mila.12165

Pratto, F., \& Glasford, D. E. (2008). Ethnocentrism and the value of a human life. Journal of Personality and Social Psychology, 95(6), 1411-1428. doi:10.1037/a0012636

Uhlmann, E. L., Pizarro, D. A., Tannenbaum, D., \& Ditto, P. H. (2009). The motivated use of moral principles. Judgment and Decision Making, 4(6), 476-491. journal.sjdm.org/9616/jdm9616.pdf

Rainey, C. (2014). Arguing for a negligible effect. American Journal of Political Science, 58(4), 1083-1091. doi/full/10.1111/ajps.12102

Shapiro, D. N., Chandler, J., \& Mueller, P. A. (2013). Using Mechanical Turk to study clinical populations. Clinical Psychological Science, 1(2), 213-220. doi/full/10.1177/2167702612469015

Shtulman, A., \& Tong, L. (2013). Cognitive parallels between moral judgment and modal judgment. Psychonomic Bulletin \& Review, 20(6), 1327-1335. doi:10.3758/s13423-0130429-9

Simpson, A., Laham, S. M., \& Fiske, A. P. (2016). Wrongness in different relationships: Relational context effects on moral judgment. The Journal of Social Psychology, 156(6), 594-609. doi.org/10.1080/00224545.2016.1140118

Walzer, M. (1977). Just and Unjust Wars: A Moral Argument with Historical Illustrations. (4 ${ }^{\text {th }}$ ed.). New York, NY: Basic Books.

Watkins, H. M. (2019). The morality of war: A review and research agenda. Conditionally accepted for publication in Perspectives on Psychological Science.

Watkins, H. M., \& Goodwin, G. (2019). A fundamental asymmetry in judgments of soldiers at war. Accepted for publication in the Journal of Experimental Psychology: General Preprint: https://doi.org/10.31219/osf.io/m7kvc

Watkins, H. M., \& Laham, S. (2018a). The influence of war on moral judgments about harm. European Journal of Social Psychology, 0(0), 1-14. doi:10.1002/ejsp.2393 
Watkins, H. M., \& Laham, S. (2018b). The principle of discrimination: Investigating perceptions of soldiers. Group Processes and Intergroup Relations, 0(0), 1-21. doi/10.1177/1368430218796277

Young, L., \& Phillips, J. (2011). The paradox of moral focus. Cognition, 119(2), 166-178. doi:10.1016/j.cognition.2011.01.004 


\section{SUPPLEMENTAL MATERIALS}

1. Pre-study

2. Full scenarios and target actions

3. Power analysis

4. Full map of possible results, highlighting key tests and key possible null results

5. Section of Phillips and Cushman results on which we based the smallest effect size of interest for equivalence testing

6. Analyses repeated without the final exclusions criteria applied $(<1,500 \mathrm{~ms}$ in reflective condition) 


\section{Pre-Study}

The aim of this pre-study was to test the assumption (and intuition) that some actions that are judged as immoral in an everyday context, are judged as less immoral in a war context. We also expected that while this would be true for many actions, it would not be the case that all is fair in war; some very immoral actions would be judged as immoral in both peace and war. Full materials and data are available on the OSF: https://osf.io/hs58y/

\section{Method}

We pre-tested our scenarios and actions (described in the main manuscript), in a study modelled on the procedures of Phillips \& Cushman, 2017, Supplementary Text. Two-hundredand-fifty participants, recruited through Amazon MTurk, were assigned to either the "war" or "peace" context, and to either a "immorality" or a "unlikelihood" condition. For example, the introductory text in the peace-likelihood condition read "In this study you will read a story and say whether different actions are likely or unlikely. These stories are all about regular people, going about their daily lives and facing various potentially challenging situations. Please take a moment to think about what this might be like." All participants were then presented with all three scenarios (described in the main manuscript), in a random order. Under each scenario, all 24 target actions (also described in the main manuscript) were listed, in a random order. Participants in the unlikelihood condition answered the question "How likely is [agent] to [action]?" on a scale from 1 (very likely) to 5 (very unlikely); while the participants in the immorality condition answered the question "How morally wrong would it be for [agent] to [action]?" on a scale from 1 (totally morally fine) to 5 (totally morally wrong). In both conditions, participants could also respond "NA" to any action.

\section{Results}

Results are presented in Figure S1 below. Any "NA" responses were excluded; hence the varying degrees of freedom in the below analyses. 
Consistent with Phillips and Cushman (2017), in the peace context the ordinary actions were seen as more likely than the improbable actions, $t(65)=16.018, p<.001$; mean difference $=1.57,95 \% \mathrm{Cls}[1.38,1.77]$, and more moral than the immoral actions, $t(62)=16.787, p<.001$; mean difference $=2.50,95 \%$ Cls $[2.21,2.80]$. The ordinary actions were also seen as more moral than the immoral-plus actions, $t(61)=17.086, p<.001$; mean difference $=3.09,95 \% \mathrm{Cls}$ $[2.73,3.45]$. The immoral-plus actions were seen as both less moral, $t(61)=8.643, p<.001$; mean difference $=0.59,95 \%$ Cls $[0.45,0.72]$ and less likely, $t(65)=9.116, p<.001$; mean difference $=0.44,95 \%$ Cls $[0.34,0.54]$, than the merely-immoral actions, suggesting that we successfully heightened the degree of immorality for these actions.

The important comparison for our purposes, however, was the comparison between war and peace. As hypothesized (and reported in the main manuscript), the immoral actions were seen as less immoral in war $(M=3.52, S D=0.83)$ than in peace, $M=3.95, S D=0.79 ; t(120)=$ 2.938, $p=.004$, mean difference $=0.43,95 \% \mathrm{Cls}[0.14,0.72]$. The immoral-plus actions, on the other hand, were not significantly affected by context, $t(119)=-0.339, p=.735$, but were seen as quite morally wrong overall (war: $M=4.58, S D=0.58$; peace: $M=4.53, S D=0.84$; mean difference $=-0.04,95 \%$ Cls $[-0.21,0.22])$. Nor did we observe an effect of context on how moral the ordinary, $t(120)=-0.441, p=.660$, mean difference $=-0.07,95 \%$ Cls $[-0.39,0.25]$; impossible, $t(48)=0.248, p=.805$, mean difference $=.08,95 \%$ Cls $[-0.56,0.72]$; and improbable, $t(120)=0.909, p=.365$, mean difference $=0.14,95 \%$ Cls $[-0.17,0.45]$, actions were rated. ${ }^{13}$ These results are illustrated in Figure S1.

\footnotetext{
${ }^{13}$ The $d f$ for the impossible actions is lower than the others because a large number of participants responded "NA". This makes sense, since it is probably hard to judge the morality of impossible actions (e.g., turning a person into a flower).
} 

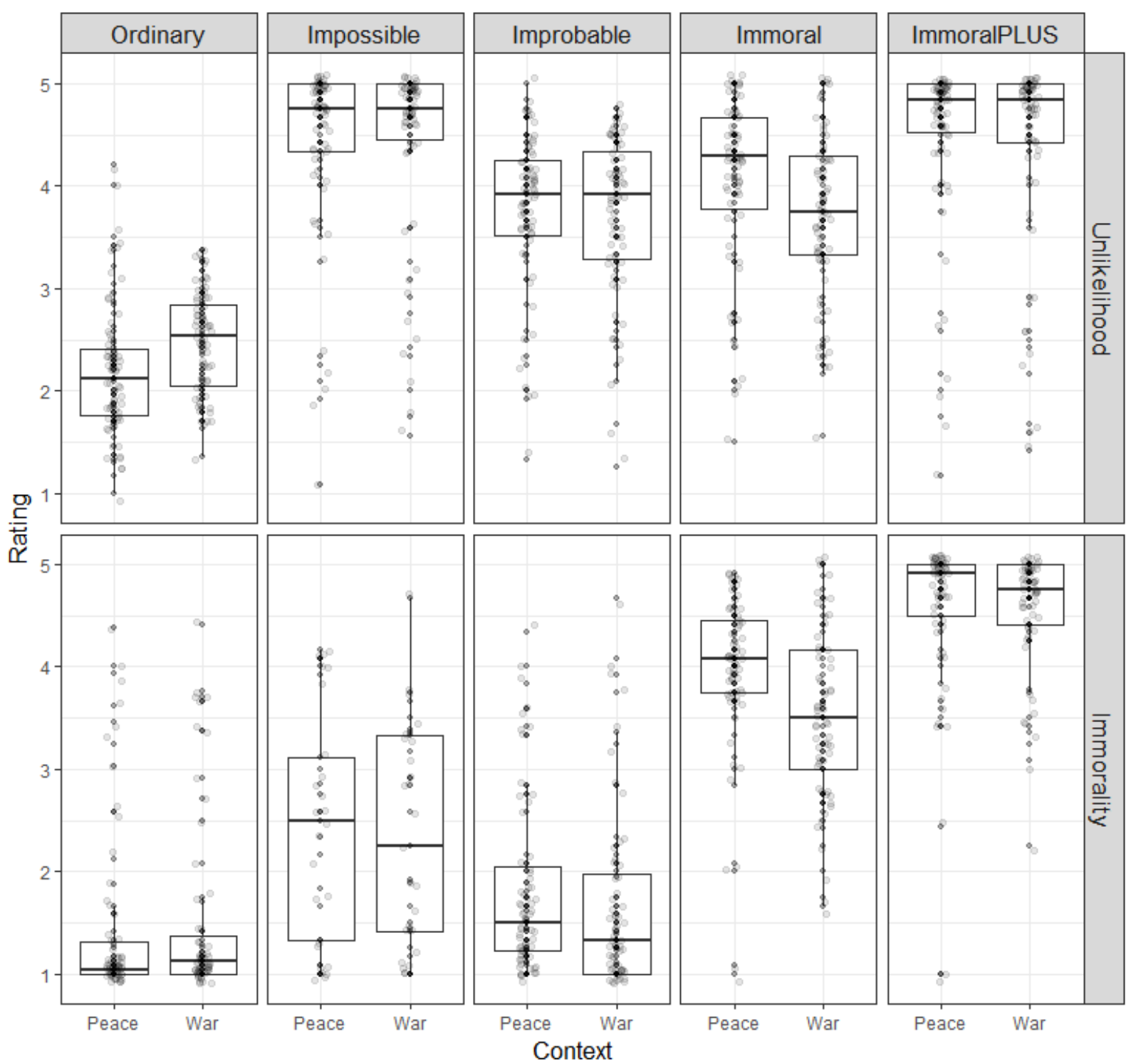

Figure S1: Illustration of the effect of context (peace vs. war) on ratings of unlikelihood (top panels) and immorality (bottom panels), for the five types of action. Ratings were made on a scale from 1 to 5 . The bottom and top of the box-plots indicate the 25th and 75th percentiles, respectively. The middle horizontal line indicates the median (50th percentile). Individual data points are indicated by the grey-shaded dots.

For ratings of likelihood, the ordinary actions were seen as slightly less likely in war $(M=$ $2.47, S D=0.50)$ than in peace $(M=2.20, S D=0.65), t(127)=2.596, p=.011$, mean difference $=-0.27,95 \%$ Cls $[-0.47,-0.06]$; while the immoral actions were seen as slightly more likely in war $(M=3.70, S D=0.80)$ than in peace, $M=4.05, S D=0.86, t(127)=2.347, p=.020$, mean difference $=0.34,95 \%$ Cls $[0.05,0.63]$. We did not observe a difference in perceived likelihood 
across war and peace contexts for the impossible, $t(118)=0.113, p=.910$, mean difference $=$ $0.02,95 \%$ Cls $[-0.30,0.34]$; improbable, $t(127)=0.393, p=.695$, mean difference $=0.05,95 \%$ Cls [-0.22, 0.33]; or immoral-plus, $t(127)=0.598, p=.551$, mean difference $=0.16,95 \%$ Cls [$0.22,0.41]$, actions. See Figure $S 1$ for an illustration of these effects.

\section{Discussion}

Overall, the results in the peace context are consistent with the findings of Phillips and Cushman (2017). And, we have demonstrated that the original immoral actions are seen as less immoral (and more likely) in war than in peace; while there are also some immoral-plus actions that are immoral even in war, and for which we also see no difference in perceived likelihood across contexts. This means that in the proposed study, we expected that the default moralpossibility constraint would be eliminated or attenuated for the immoral vs. ordinary actions in war, but it would be present for the immoral-plus vs. ordinary actions in both war and peace. Full scenarios and actions are included below, and can be found on the Open Science Framework as well: https://osf.io/hs58y/ 


\section{FULL MATERIALS (See also Testable file here: https://osf.io/gvfbd/)}

\section{Instructions}

Peace [with image]

In this part you will read a story and say whether different actions are possible or impossible. These stories are all about regular people, going about their daily lives and facing various potentially challenging situations. Please take a moment to think about what this might be like.

War [with image]

In this part you will read a story and say whether different actions are possible or impossible. These stories are all about soldiers, operating in a war zone and facing various potentially challenging situations. Please take a moment to think about what this might be like.

\section{Scenario 1}

Peace

Josh is on the way to the airport with his friends: They are going to catch a flight for a hunting safari in Africa. They leave with plenty of time to make it there, but their car breaks down on the way. Now Josh is sitting in the car near a busy intersection, and knows they need to get to airport soon if they are going to catch their flight.

War

Josh is the commander of a military unit, on the way to the airport with his men: They are going to catch a flight to a military base in another part of the country, to complete a mission there. They leave with plenty of time to make it there, but their Humvee breaks down on the way. Now Josh is sitting in the vehicle near a busy intersection, and knows they need to get to the airport soon if they are going to catch their flight and complete their mission.

Ordinary events

1. Reschedule for a later flight

2. Ask a gas station clerk for help

3. Take a public bus there

4. Request airport shuttle pickup/Request that airport sends vehicle to pick them up

5. Ask relative to pick him up/Contact sergeant to ask for assistance

6. Hail a taxi

7. Call a friend for a ride/Call another unit for a ride

8. Take public transportation

Impossible events

9. Get a new vehicle by thinking

10. Ride a cat to the airport

11. Teleport themselves to the airport

12. Levitate and fly to the airport 
Immoral events

13. Take another person's car without asking

14. Take a taxi without paying

15. Without asking, trade his friend's bags for a ride/without asking, trade his men's equipment for a ride

16. Sneak onto public transportation

Immoral even in war

17. Kill a person to take their car/kill a civilian to take their car

18. Take another driver hostage/take a civilian driver hostage

19. Threaten to kill a child unless someone drives them

20. Torture another person until they give up their car

Improbable events

21. Beckon a friend passing by

22. Convince airport to delay flight

23. Get a stranger to drive them

24. Ask the plane to take a detour and pick them up

\section{Scenario 2}

\section{Peace}

Brad is leading a group of his friends, while hiking through the mountains in the Canadian wilderness. A couple of days into their hike, Brad realizes that they are lost. He knows that a rescue crew could arrive before long, but it is extremely cold and they don't have much food or water left.

\section{War}

Brad is the commander of a military unit, leading his men through the mountains in hostile territory. A couple of days into their mission. Brad realizes that they are lost. He knows that a rescue crew could arrive before long, but it is extremely cold and they don't have much food or water left.

\section{Ordinary events}

25. Stay put and wait for help

26. Follow a river out of the wilderness

27. Alert rescuers with emergency radio

28. Find a river for fresh water and fish

29. Get more food by hunting and fishing

30. Create a shelter to stay warm

31. Be found by the rescue crew

32. Find edible berries, leaves, and roots 
33. Use his mind to keep everyone warm

34. Make new jackets from pine trees

35. Alert airplanes overhead by yelling

36. Grind up rocks for food and water

Immoral events

37. Rob other hikers they meet/Rob any civilians they meet

38. Kill his friend's pet dog for food/Kill a goat from a village's herd

39. Force his friends to hunt for food/force his men to hunt for food

40. Loot any cabins they come across/Loot any enemy hideouts that they come across

Improbable events

41. Find thermal vents to keep warm

42. Find signs showing the path out

43. Meet a former expedition guide who helps them

44. Find an abandoned bear cave

Immoral even in war

45. Secretly take his friend's/men's food

46. Leave the weakest people behind

47. Kill any hikers/civilians they meet to take their food

48. Torture any hikers/civilians they meet until they give up their food

\section{Scenario 3}

Peace

Adam has a day off from work, and is on his way to a shopping mall near his house to buy a gift for his wife. About half way there, he gets the feeling that someone is following him. When he looks around he sees a group of men dressed in fatigues glaring at him and talking to each other. One of them suddenly runs towards him.

War

Adam has a day of leave, and is on his way to a market near the military base to buy a souvenir for his wife. About half way there, he gets the feeling that someone is following him. When he looks around he sees a group of men dressed in fatigues glaring at him and talking to each other. One of them suddenly runs towards him.

\section{Ordinary events}

49. Ask the man what is happening

50. Stand his ground

51. Ask for help from a passerby

52. Step into a nearby shop

53. Yell out to attract attention 
54. Take out his phone/radio to call for help

55. Try to get out of the way of the man

56. Hail a cab and drive away

Impossible events

57. Make himself invisible

58. Conjure up a magic shield around himself

59. Turn the men into flowers

60 . Teleport away to the shopping mall/market

Immoral events

61. Shoot the man

62. Attack the man with a knife

63. Steal someone's car to get away

64. Jump on a bus without paying

Improbable

65. Distract the man by pointing to a passing bird

66 . Find an enormous sculpture to hide behind

67. Discover that the man is a long lost family member

68 . Help the man when he trips over a passing cat

Immoral even in war

69. Grab a passerby to use as a human shield if the man attacks

70. Hold a child hostage as protection

71. Capture the man and torture him to find out who he is

72. Shoot the man and mutilate his corpse

Interested readers can try the study "as a participant" at this link: testable.org/t/140215c728 


\section{POWER ANALYSIS}

There is currently no complete way to conduct a power analysis for multi-level logistic regressions (without knowing how to simulate/code extensively). However, we were able to use an online app, available here: https://myshinyapps-0o.shinyapps.io/multi-level-logisticregression/, which provides a good approximation of what we needed. The app is described here: https://psychometroscar.com/2018/07/31/power-analysis-for-multilevel-logistic-regression/ (Astivia, Gadermann, \& Guhn, 2019; Bates, Maechler, Bolker \& Walker, 2014).

The limitations of this app (for our use) are that it does not allow precise specification of the research design (instead, the user simply inputs the sample sizes at Level 1 and Level 2), that it only allows a single random intercept and random slope, and that it only allows a single two-way interaction between covariates. These limitations notwithstanding, we describe its inputs and outputs below, and include a discussion of how we arrived at our final proposed sample size of 1600.

\section{Inputs when Testing Power to Replicate the Phillips and Cushman Effect (i.e., Peace Context Only)}

\section{Sample sizes}

\section{Level 1: 3}

In our study design, Level 1 is the scenarios (responses to target actions are clustered within scenarios). There are 3 scenarios only.

\section{Level 2: 750}

In our study design, Level 2 is the participants (scenarios are clustered within participants). We are proposing to recruit 1600 participants, but anticipate excluding some (see analysis plan). Half the remaining participants (750) will be allocated to the peace context, and half to the war context.

\section{Random effects}

We used the Phillips and Cushman data and code to estimate random effects coefficients (as well as fixed effects coefficients in the next section). However, to accommodate the limitations of the present app, we decided to exclude the scenario random intercept (it was very small), in favor of focusing on the participant random intercept and random slope.

Intercept variance: $\mathbf{0 . 1 1 1}$

Covariate:

Slope variance:

\subsection{4}

\section{Covariates}


We used the Phillips and Cushman data and code to estimate the coefficients for the fixed effects (main effects and interactions). Again, to accommodate the limitations of the present app, before fitting the Phillips and Cushman model we re-coded the Type of Action variable to become a binary variable with two levels ("immoral" vs. "other") rather than a five-level factor. This is why the probability of $x 1$ ("immoral") is 0.2 in this section.

$\begin{array}{ll}\begin{array}{l}\text { Number of covariates: } \\ \text { Intercept beta: }\end{array} & \begin{array}{l}2 \text { (Type of Action = x1; Time Pressure Condition = x2) } \\ \text {-0.56 }\end{array} \\ & -1.28 \\ \text { x1 beta: } & \text { Level } 1 \\ \text { x1 level: } & \text { Binomial } \\ \text { x1 distribution: } & 0.2 \\ \text { x1 probability: } & \\ & -0.19 \\ \text { x2 beta: } & \text { Level } 2 \\ \text { x2 level: } & \text { Binomial } \\ \text { x2 distribution: } & 0.5 \\ \text { x2 probability: } & \\ & 1.3\end{array}$

Number of replications for the simulation: $\mathbf{3 0}$

Output of Power Analysis

Given the parameters described above, the app indicated that our power was as follows:

Fixed effects

Intercept: $\quad>99 \%$

$x 1$ (Type of Action) $\quad>99 \%$

$x 2$ (Condition) $\quad 43 \%$

$x 1^{*} \times 2$ interaction $\quad 90 \%$

\section{Random effects}

Intercept $\quad 0 \%$

Slope $\quad 7 \%$ 


\section{MAP of POSSIBLE RESULTS and OUR PROPOSED INTERPRETATIONS}

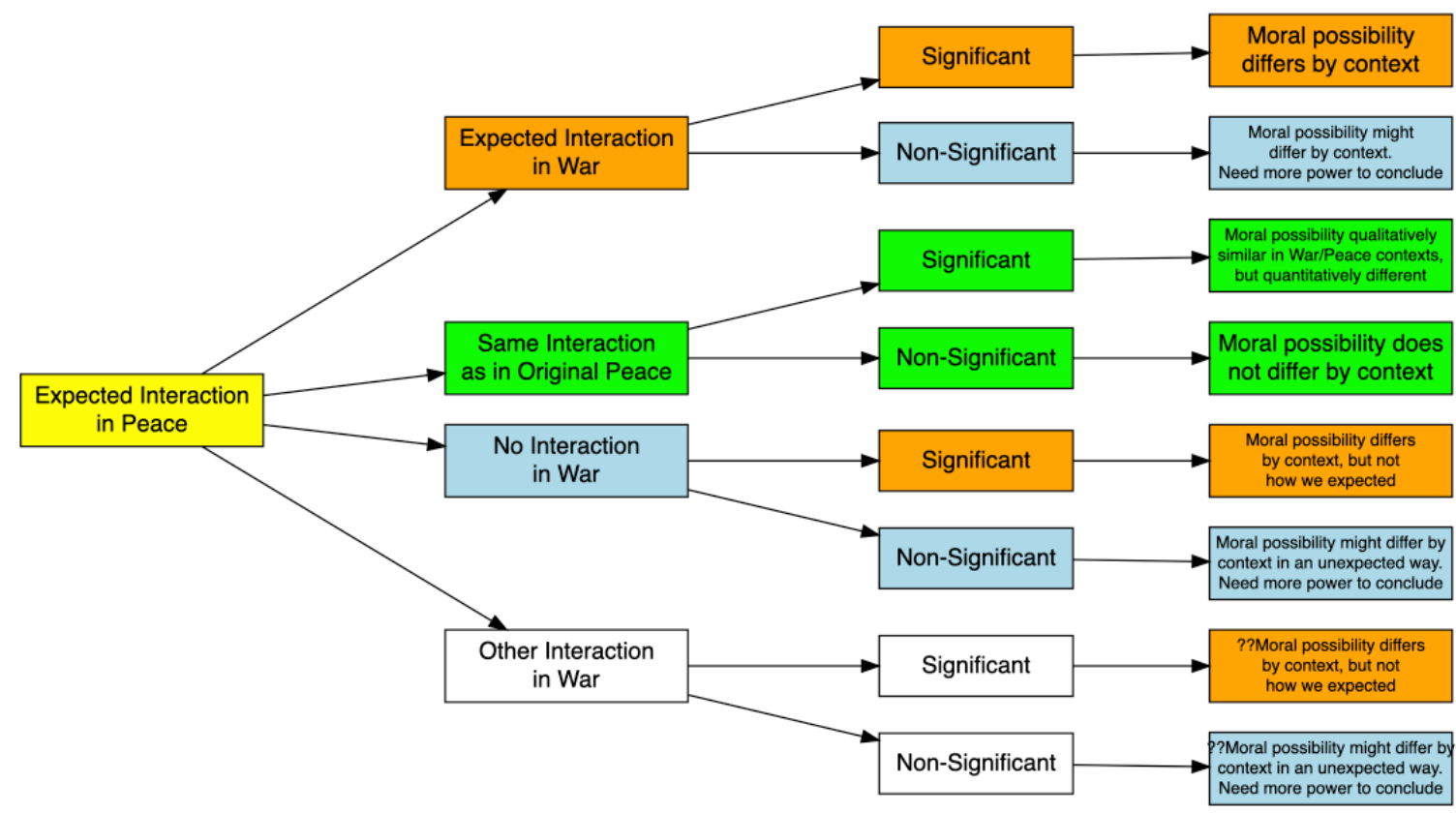

Analytis \#1:

Analytis \#2:

Analytis \#3:

Replicating PC in Peace Context Replicating PC in War Context Testing Three-way Interaction

Our Interpretation

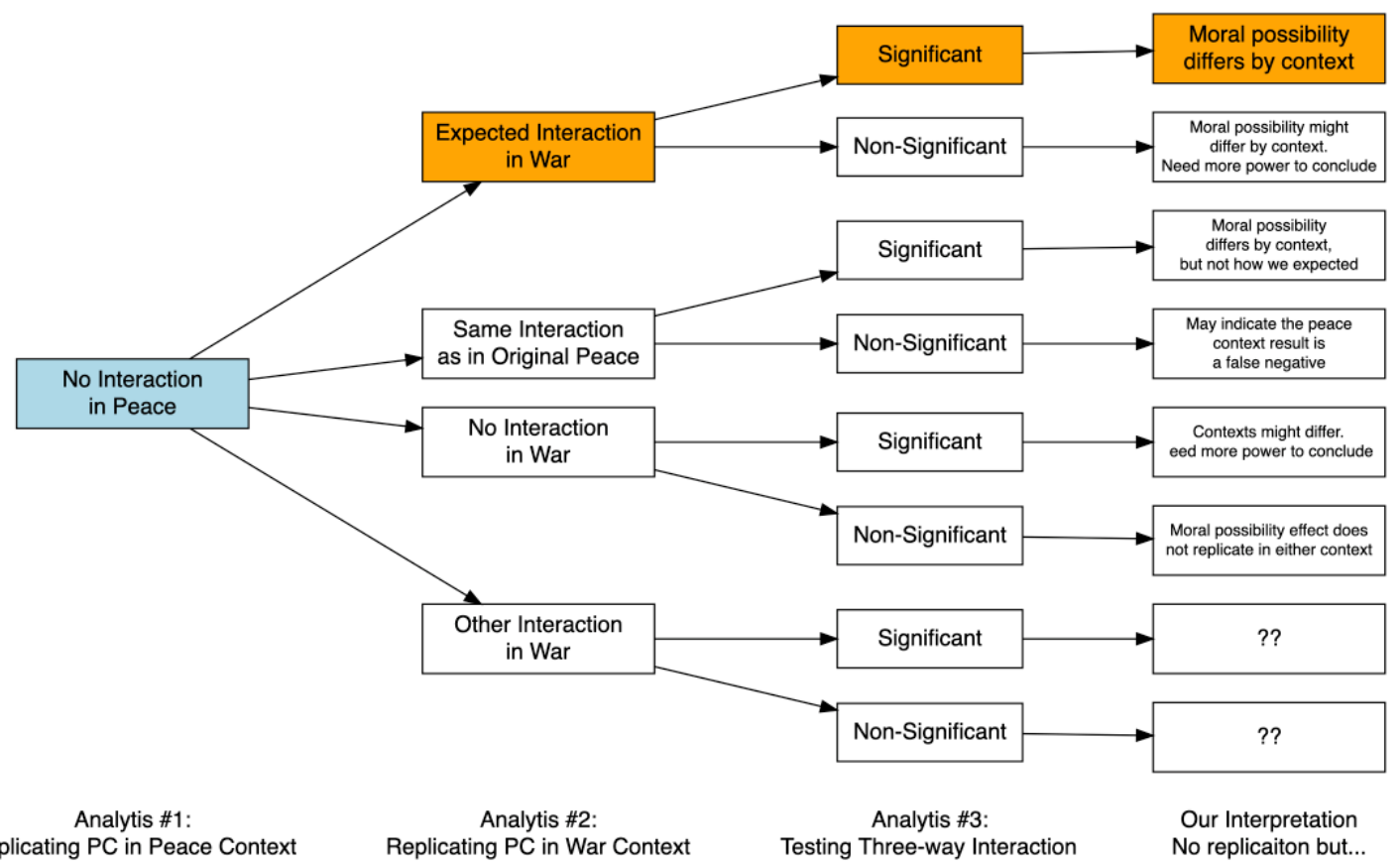

\section{Section of Phillips and Cushman results used for calculation of SESOI for equivalence}




\section{test}

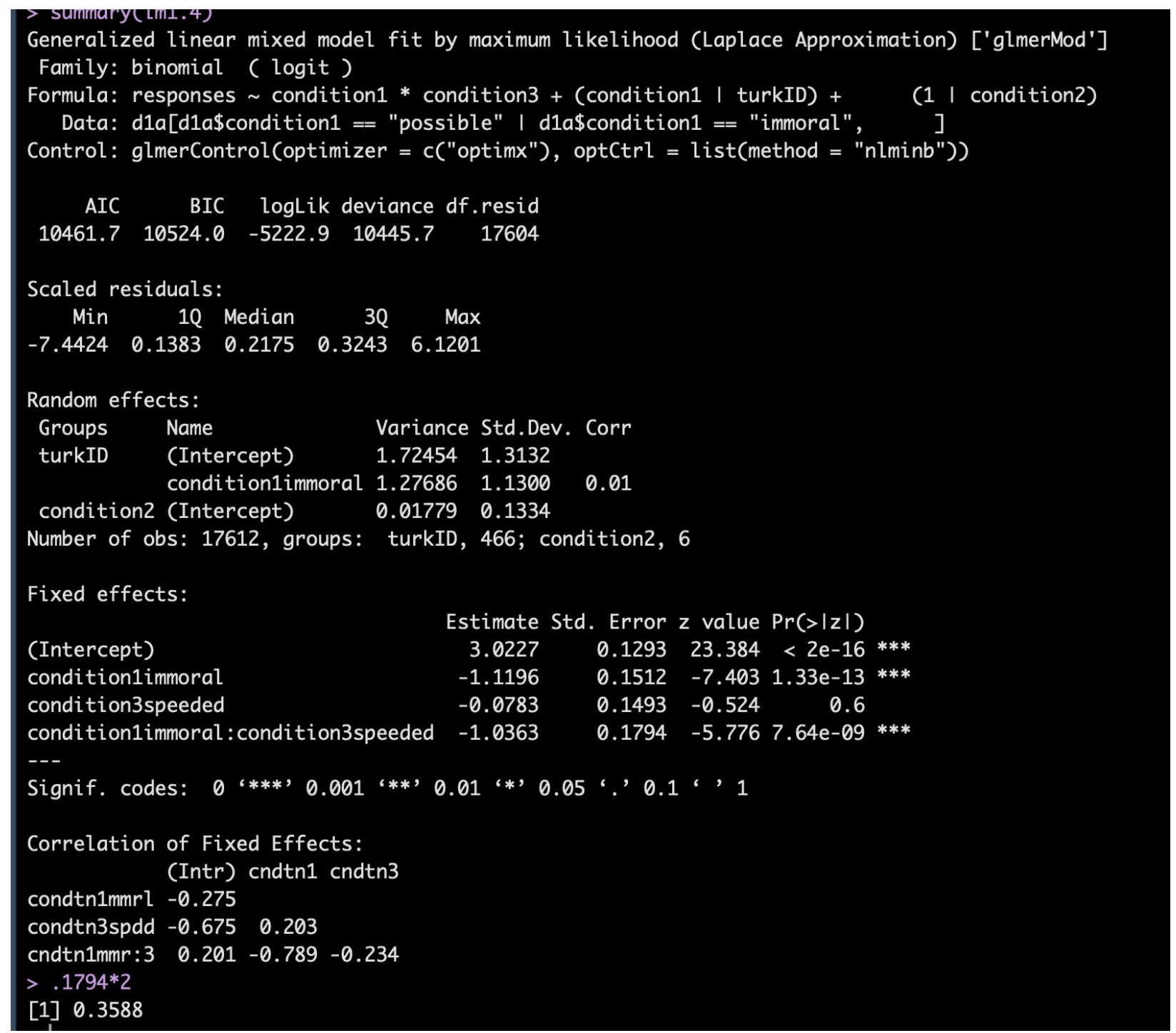

The type of action (ordinary vs. immoral) by condition (speeded vs. reflective) interaction is -1.036 , with a standard error of 0.179 . This means that the smallest effect Phillips and Cushman could have detected for this interaction is approximately 0.359 . We therefore used $b_{\text {small }}=|0.35|$ for our equivalence tests. (Note that Phillips and Cushman don't report this particular interaction in their main manuscript.) 


\section{Analyses repeated without the last set of exclusions (responses made in $<1,500 \mathrm{~ms}$ in reflective condition)}

\section{Peace context}

As with the main analyses, we first selected only the peace context, and regressed the response variable (possible vs. impossible) on time pressure condition (speeded vs. reflective), type of action (5 levels), and their interaction. We also entered scenario as a random intercept, and the effect of type of action was set to vary across participants (random slope). The key effect is the interaction between type of action and time pressure condition, which indicates the moral-possibility constraint: This interaction was significant, $X^{2}(4)=170.40, p<.001$.

Then, to break down this interaction, we tested the effect of condition (speeded vs. reflective) for each type of action separately. The immoral and immoral-plus actions were judged as more impossible in the speeded condition than in the reflective condition (immoral: B $=-0.656, \mathrm{SE}=0.16, p<.001$; immoral-plus: $\mathrm{B}=-1.690 \mathrm{SE}=0.23, p<.001)$. In other words, without these exclusions, we again replicate in the peace context the moral-possibility constraint originally observed by Phillips and Cushman (2017). And, we replicated the post hoc analysis showing that the effect of time pressure was larger for the immoral-plus than the merely-immoral actions, interaction: $\mathrm{B}=-0.542, \mathrm{SE}=0.12, p<.001 .{ }^{14}$

However, in contrast to the main analyses, the ordinary and improbable actions were also affected by condition (ordinary: $\mathrm{B}=-0.801, \mathrm{SE}=0.15, p<.001$; improbable: $\mathrm{B}=-0.216$, SE $=0.10, p=0.033$ ), as were the impossible actions, albeit in the opposite direction: $B=1.397$, $\mathrm{SE}=0.11, p<.001$. Figure $\mathrm{S} 2$ illustrates these results.

\footnotetext{
14 This model was fitted without the scenario random effect, and without the random slope of type of action by participant, because the planned analysis failed to converge.
} 


\section{Peace Context without Exclusions}

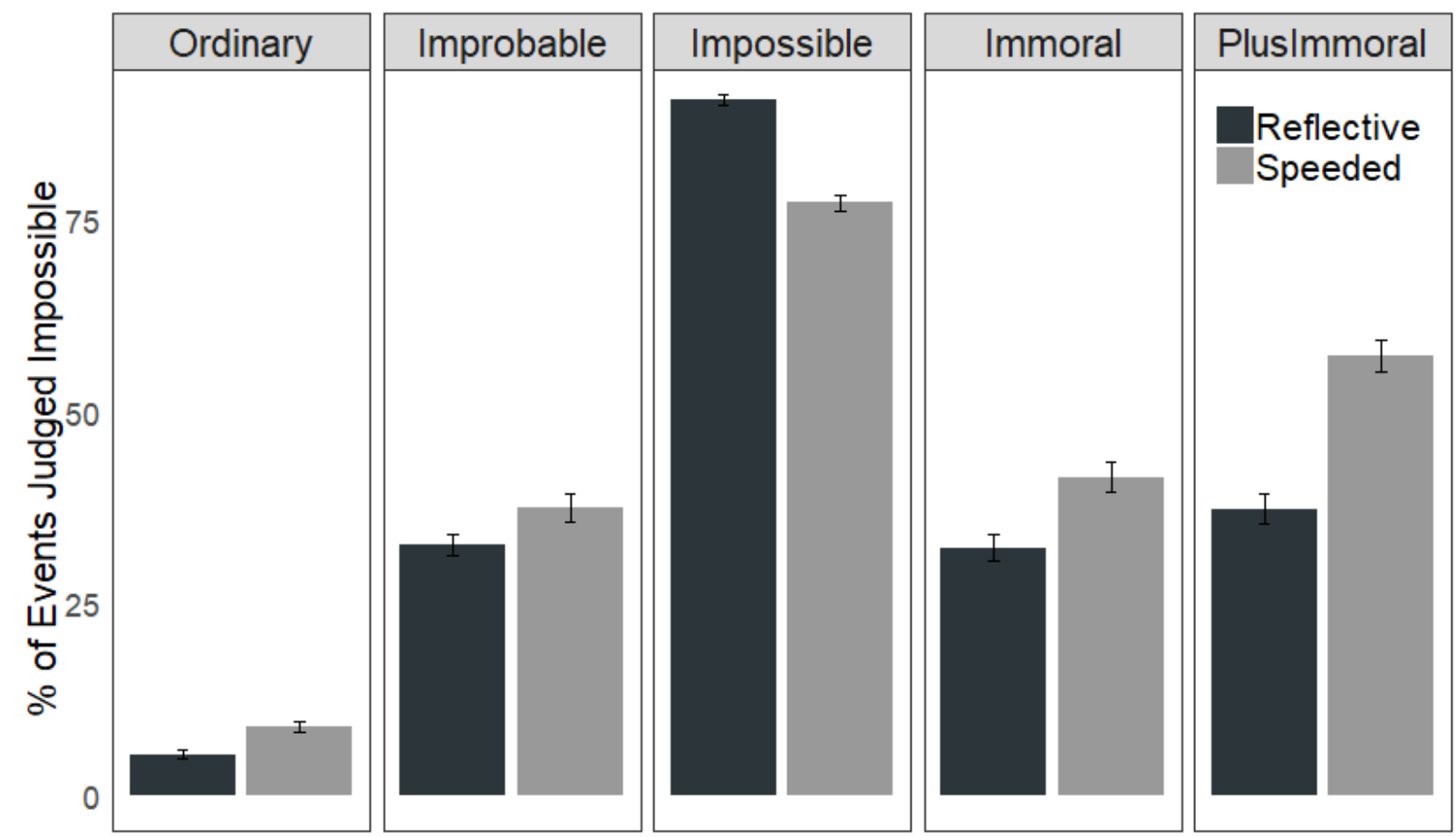

Figure S2: Illustration of the effect of time pressure condition (reflective vs. speeded) in the peace context, for each type of action, without excluding participants who responded in $<1,500 \mathrm{~ms}$ in the reflective condition. Error bars represent $+/-1$ standard error of the mean.

Next, we conducted the same analyses for only the war context. The null-model failed to converge. However, the model of interest - with type of action, time pressure condition, and their interaction as fixed effects; scenario as a random intercept, and a random slope of type of action by participant - revealed a significant interaction between the immoral type of action and time pressure condition, $\mathrm{B}=-0.403, \mathrm{SE}=0.19, p=.031$, as well as a significant interaction between immoral-plus type of action and time pressure condition, $\mathrm{B}=-0.875, \mathrm{SE}=0.32, p=$ .006. We therefore next tested the effect of condition (speeded vs. reflective) for each type of action separately. The immoral and immoral-plus actions were judged as more impossible in the speeded condition than the reflective condition (immoral: $\mathrm{B}=-1.000, \mathrm{SE}=0.19, p<$ 
$.001 ;{ }^{15}$ immoral-plus: $\left.\mathrm{B}=-1.381, \mathrm{SE}=0.30, p<.001\right)$. In contrast to in the main analysis, in this context the effect was not significantly larger for the immoral-plus than the merely-immoral actions, interaction: $\mathrm{B}=-0.472, \mathrm{SE}=0.30, p=.111$.

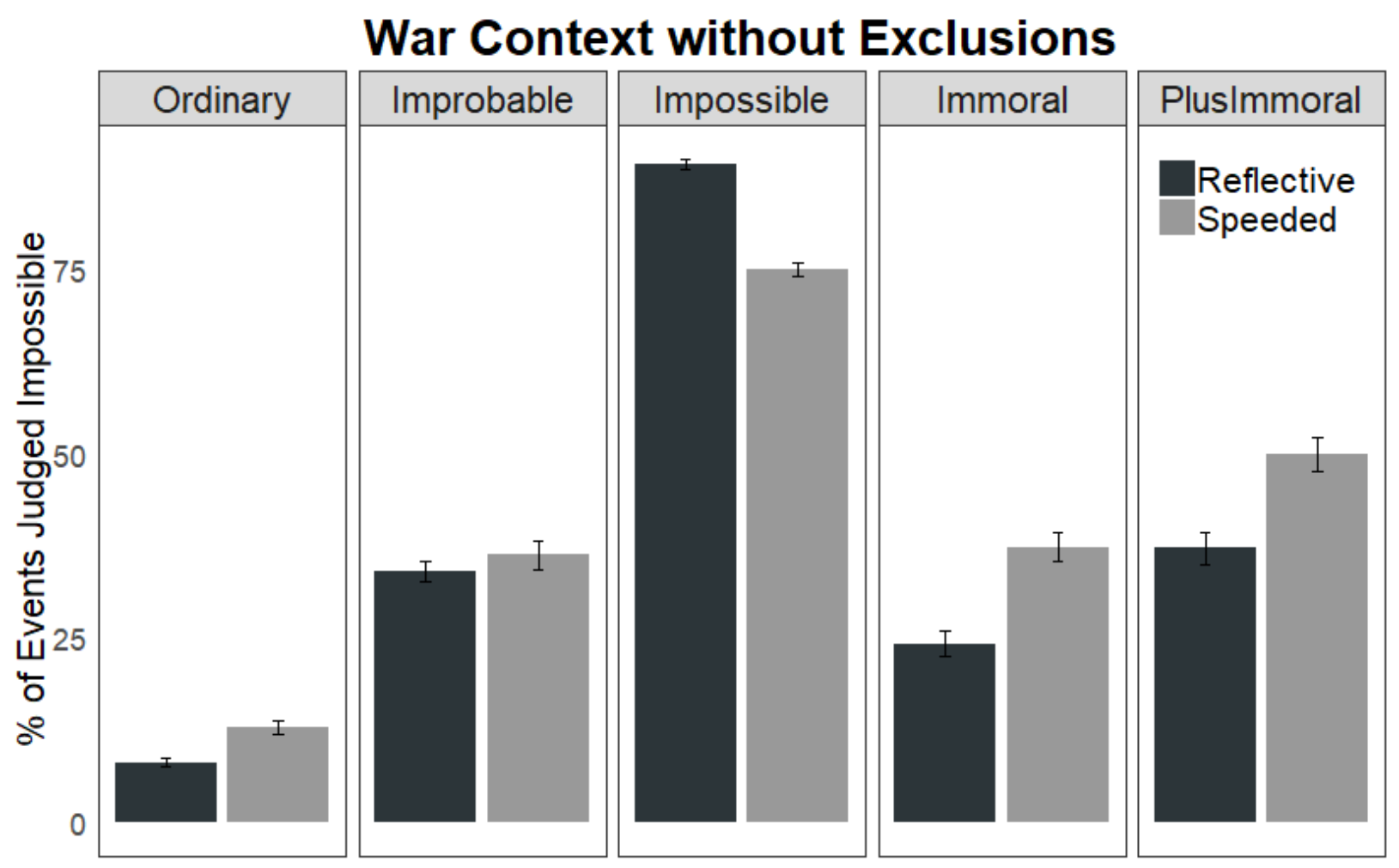

Figure S2: Illustration of the effect of time pressure condition (reflective vs. speeded) in the peace context, for each type of action, without excluding participants who responded in $<1,500 \mathrm{~ms}$ in the reflective condition. Error bars represent $+/-1$ standard error of the mean.

The improbable actions were not affected by condition; $\mathrm{B}=-0.117, \mathrm{SE}=0.11, p=.305$ ). But, the ordinary actions were, $B=-0.621, \mathrm{SE}=0.12, p<.001$. The impossible actions were

\footnotetext{
${ }^{15}$ This model was fitted without the random effect of scenario, because the planned model failed to converge.
} 
affected by condition (but in the reverse direction; $B=1.320, S E=0.10, p<.001$ ). These results are illustrated in Figure S3.

Finally, to test the three-way interaction between context, type of action, and time pressure condition, we fitted the same full model to the full data set as reported in the main manuscript. This model failed to converge. We therefore fitted a model with no random intercept of scenario, and no random slope of type of action by participant ID (i.e., this model had only a random intercept of participant ID, in addition to the fixed effects). In this model, the three-way interaction between condition, context, and immoral actions was not significant, $B=-0.289, S E$ $=0.15, p=.052$ (same as in the main analyses). An equivalence test again indicates that the $90 \% \mathrm{Cl}$ around this effect includes the SESOI, [-0.534, -0.044], which means that we cannot rule out the possibility of a small effect that we failed to detect.

Further, in this model, the three-way interaction between condition, context, and immoral-plus actions was also non-significant; $\mathrm{B}=0.274, \mathrm{SE}=0.15, p=.061$. And, a $90 \% \mathrm{Cl}$ around this effect also includes the SESOI, [0.033, 0.515], which again means that we have an inconclusive pattern of results for this type of action.

Overall, although we have generally replicated - in this data set, with fewer exclusions the pattern of effects reported in the main manuscript, the same levels of significance did not always hold. This might mean that the effects we are interpreting - especially the three-way interactions - are not as robust as would be ideal. However, this final set of exclusion criteria was meant to apply to fast participants; if there is a speed-accuracy trade-off then leaving these participants in the data set also means leaving in more noise, in turn making the signal (a threeway interaction) harder to detect. 